\title{
Promoting healthy timing and spacing of births in India through a community-based approach
}

\author{
M.E. Khan \\ Population Council \\ Mary Philip Sebastian \\ Population Council \\ Usha Sharma \\ Rukma Idnani \\ Kaushal Kumari \\ Population Council
}

See next page for additional authors

Follow this and additional works at: https://knowledgecommons.popcouncil.org/departments_sbsr-rh

Part of the Demography, Population, and Ecology Commons, International Public Health Commons, Maternal and Child Health Commons, and the Public Health Education and Promotion Commons How does access to this work benefit you? Let us know!

\section{Recommended Citation}

Khan, M.E., Mary Philip Sebastian, Usha Sharma, Rukma Idnani, Kaushal Kumari, Bharati Maheshwari, and Shahid Ashraf. 2008. "Promoting healthy timing and spacing of births in India through a community-based approach," FRONTIERS Final Report. Washington, DC: Population Council. 


\section{Authors}

M.E. Khan, Mary Philip Sebastian, Usha Sharma, Rukma Idnani, Kaushal Kumari, Bharati Maheshwari, and Shahid Ashraf 


\title{
Promoting Healthy Timing and Spacing of Births in India through a Community-based Approach
}

\author{
FRONTIERS Program, Population Council \\ Dr. M.E. Khan \\ Dr. Mary Philip Sebastian
}

\author{
Lala Lajpat Rai Memorial Medical College, Meerut \\ Dr. Usha Sharma \\ Dr. Rukma Idnani \\ Dr. Kaushal Kumari \\ Dr. Bharati Maheshwari
}

\section{Department of Economics, Jamia Milia Islamia University, Delhi Dr. Shahid Ashraf}

This project was made possible by the generous support of the American people through the United States Agency for International Development (USAID) under Cooperative Agreement Number HRN-A-00-98-00012-00 and In-house Project No. 5800.53106. The contents are the responsibility of the FRONTIERS Program and do not necessarily reflect the views of USAID or the United States Government.

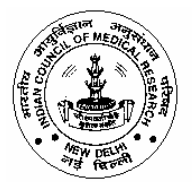




\section{EXECUTIVE SUMMARY}

The Indian Family Welfare Program, though successful in increasing contraceptive use among couples who have achieved their desired family size, has failed in educating people about the importance and need of using contraceptive methods for spacing births. The concept of interpregnancy spacing and its advantages was never given serious attention as a program objective. The latest National Family Health Survey (NFHS) results show that 77 percent of sterilized women did not use a family planning method before their sterilization (IIPS and Marco International 2007). Furthermore, available studies demonstrate that a birth interval of 3 to 5 years could increase chances of infant and maternal survival by 2.5 times more than children born at an interval of 2 years or fewer. Thus, Healthy Timing and Spacing of Pregnancy (HTSP) is considered an important family planning intervention to improve maternal and child health.

Keeping this in view, the Department of Health \& Family Welfare, Government of Uttar Pradesh, the Integrated Child Development Services (ICDS), Department of Women \& Child Development, Uttar Pradesh, the Lala Lajpat Rai Memorial Medical College, Meerut, Uttar Pradesh, the Department of Economics, Jamia Milia Islamia University, Delhi, and the Population Council's Frontiers in Reproductive Health Program (FRONTIERS), Population Council undertook a study to test a model to increase use of postpartum contraception among young pregnant women with a parity of 0 or 1 . The specific objectives were to (a) test a comprehensive Behavior Change Communication (BCC) model for its effectiveness to educate young couples and community members about healthy spacing and its advantages; and (b) increase the use of Lactational Amenorrhea Method (LAM) and postpartum contraception to expand the interval between pregnancies.

The study used a quasi-experimental pre-post control group design. It was carried out in 48 villages of the Meerut district of Uttar Pradesh, with 24 villages each in the experimental and control groups. Each study group recruited 600 women at 3 to 6 months pregnancy with parity of 0 or 1 . The women were interviewed at recruitment, four months postpartum, and nine months postpartum. In addition, their husbands and one-third of the mothers-in-law were interviewed at recruitment and nine months postpartum.

The key activities in the intervention comprised the following:

- An educational campaign by community workers (CWs) addressing pregnant women, their husbands, mothers-in-law, and community opinion leaders using Information Education and Communication (IEC) materials such as leaflets, posters, wall paintings, and a pocket booklet on HTSP.

- Before the campaign, CWs were trained on all educational topics. Three CWs from two different ministries complemented each other's educational efforts - the Auxiliary Nurse Midwife (ANM) and Accredited Social Health Activists (ASHA), both from the Ministry of Health and Family Welfare (MoH\&FW), and the village-level Anganwadi Worker (AW) from the Integrated Child Development Services (ICDS) of the Department of Women and Child Development.

- Coordination and support among the district authorities of the two departments and among the village level CWs was enhanced to create a synergic effect in their educational efforts.

- A printed work register was given to CWs to ensure systematic coverage of all relevant topics during counseling and to support their supervisors' monitoring work. 


\section{Findings}

- At baseline, counseling on postpartum care and contraception, besides other topics, was reported by less than six percent of the couples. At the nine-month postpartum follow-up interview, a significant increase was found in counseling on all topics in the experimental areas compared to the control areas.

- Eighty-eight percent of the women from the experimental area received the booklet on HTSP and reported reading it. Of those who received the booklet, 89 percent showed it to their husbands, and 49 percent of that group shared it with their mothers-in-law. Sharing the booklet with the husband also created an opportunity to discuss planning for the next child and using a contraceptive.

- Knowledge of spacing methods increased significantly in the experimental areas compared to the control areas. For instance, knowledge that an intrauterine device (IUD) could protect against pregnancy for up to 10 years increased from less than one percent at baseline to 46 percent at the nine-month postpartum follow-up. This knowledge remained at less than five percent in the control area. Eighty-four percent of women in the experimental area could state that an IUD is placed in the uterus and discuss the correct use of Oral Contraceptive Pills (OCPs). Similarly, increases in knowledge about contraceptive methods were observed among men in the experimental area compared to the control area.

- At the nine-month postpartum follow-up, 62 percent of the women in experimental sites used modern contraceptives, and 22 percent used LAM at four months postpartum, compared to 31 percent and zero percent respectively in the control group. The condom was the main method used (44\% in the experimental area and 23\% in the control area). Of the 22 percent of women who used LAM as a contraceptive, 68 percent transitioned to a modern contraceptive.

\section{Lessons Learned}

The study showed the following:

$\checkmark$ The BCC model developed to promote HTSP was effective in promoting LAM and postpartum contraception and could be rolled out easily.

$\checkmark$ Misconceptions about the return of fertility and its links to the biological marker of the menstrual cycle are the main barriers in a timely beginning of postpartum contraception.

$\checkmark$ Acceptance of CWs in a family increases if counseling focuses on HTSP and its benefits to mother, child, and family.

$\checkmark$ The complementing effort by CWs of two Ministries to achieve similar objectives is feasible and provides a synergistic effect.

The BCC materials, counseling aids, and messages developed for the projects are ready to use in scaling up the program. 


\section{TABLE OF CONTENTS}

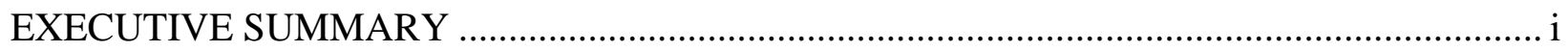

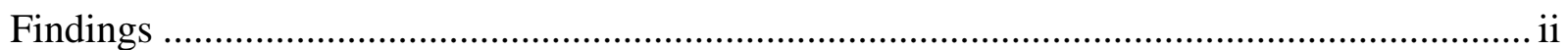

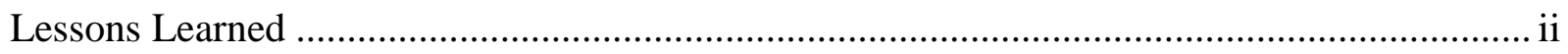

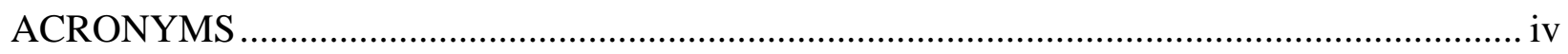

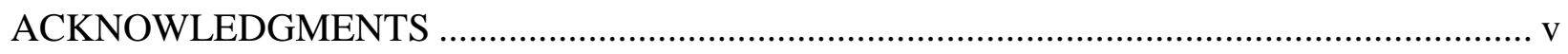

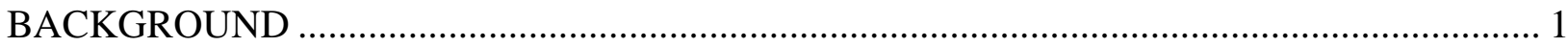

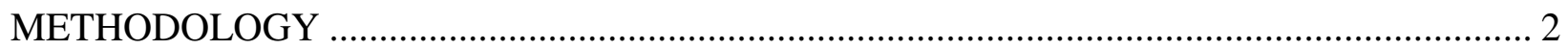



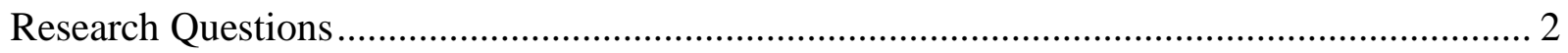



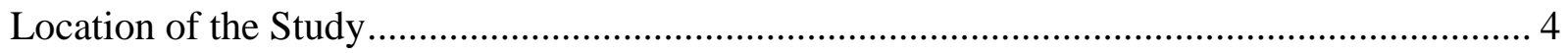

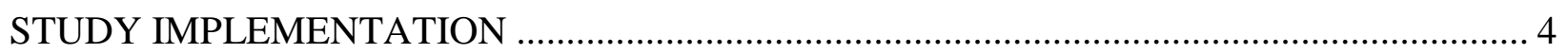

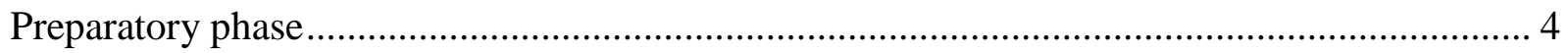

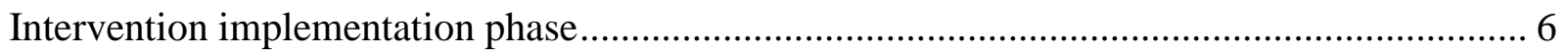

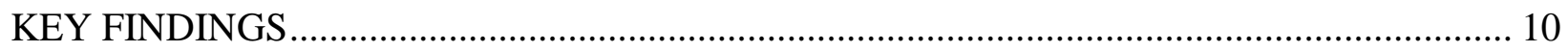

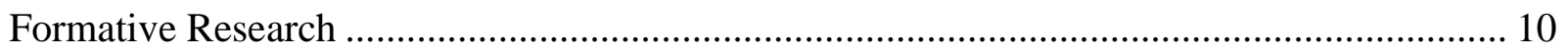

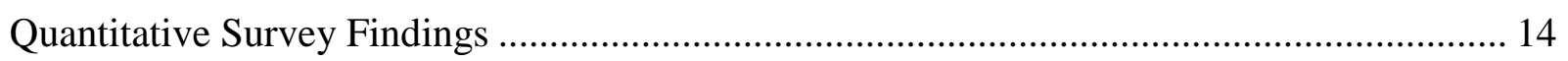

Profile of women, husbands, and mothers-in-law ............................................................ 14

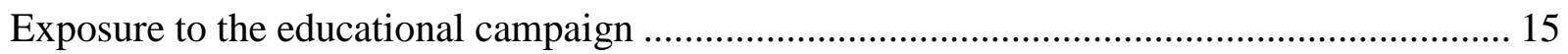

Counseling efforts by community workers ......................................................................... 15

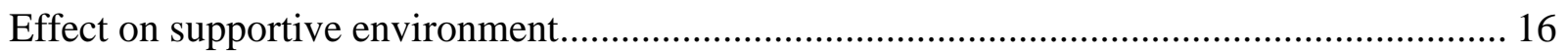

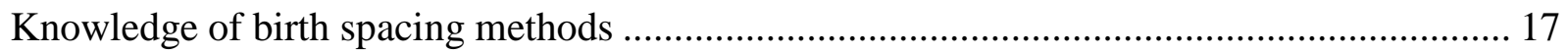

Contraceptive use at nine / ten months postpartum .............................................................. 17

DISSEMINATION AND UTILIZATION OF THE RESULTS ……………………................... 21

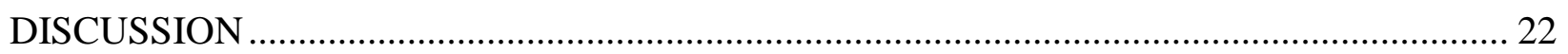

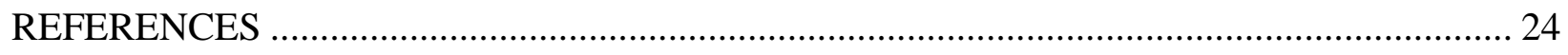

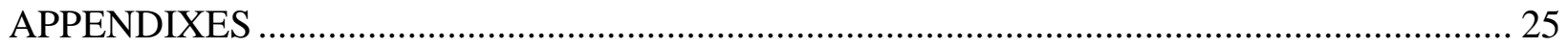




\section{ACRONYMS}

\begin{tabular}{|c|c|}
\hline ANC & Antenatal Care \\
\hline ANM & Auxiliary Nurse and Midwife \\
\hline ASHA & Accredited Social Health Activist \\
\hline AW & Anganwadi Worker \\
\hline $\mathrm{BCC}$ & Behavior Change Communication \\
\hline CDPO & Child Development Project Officer \\
\hline $\mathrm{CHC}$ & Community Health Center \\
\hline $\mathrm{CMO}$ & Chief Medical Officer \\
\hline CPR & Contraceptive Prevalence Rate \\
\hline $\mathrm{CW}$ & Community Worker \\
\hline DHS & Demographic Health Survey \\
\hline DM & District Magistrate \\
\hline DMO & District Medical Officer \\
\hline DPO & District Planning Officer \\
\hline ECP & Emergency Contraceptive Pills \\
\hline FGD & Focus Group Discussion \\
\hline FP & Family Planning \\
\hline FRONTIERS & Frontiers in Reproductive Health Program \\
\hline HRRC & Human Reproduction Research Center \\
\hline HTSP & Healthy Timing and Spacing of Pregnancy \\
\hline ICDS & Integrated Child Development Services \\
\hline ICMR & Indian Council of Medical Research \\
\hline IEC & Information Education and Communication \\
\hline IUD & Intrauterine Device \\
\hline LAM & Lactational Amenorrhea Method \\
\hline LHV & Lady Health Visitor \\
\hline MDG & Millennium Development Goal \\
\hline MHW & Male Health Worker \\
\hline MIM & Men in Maternity \\
\hline MoH\&FW & Ministry of Health and Family Welfare \\
\hline NFHS & National Family Health Survey \\
\hline NFWP & National Family Welfare Program \\
\hline $\mathrm{NGO}$ & Non-Governmental Organization \\
\hline $\mathrm{OCP}$ & Oral Contraceptive Pills \\
\hline OR & Operations Research \\
\hline PHC & Public Health Center \\
\hline PMC & Project Management Committee \\
\hline $\mathrm{PNC}$ & Postnatal Care \\
\hline RH & Reproductive Health \\
\hline SIFPSA & State Innovations in Family Planning Services Project Agency \\
\hline STIs & Sexually Transmitted Infections \\
\hline
\end{tabular}




\section{ACKNOWLEDGMENTS}

This study is a collaborative undertaking by the Population Council's Frontiers in Reproductive Health Program (FRONTIERS), the Lala Lajpat Rai Medical College, Meerut and the District Directorates of the Health and Family Welfare and Department of Women and Child Development. Without their active support and participation, it would not have been easy to implement and succeed with the program. The authors of this report would like to thank the Chief Medical Officer of the district, the Child Development Project Officer of the district, and their colleagues for extending all support to the program. We are thankful to the United States Agency for International Development (USAID) for providing resources to conduct this study. We would also like to thank the various doctors, paramedics, Anganwadi Workers (AWs), and the Accredited Social Health Activists (ASHA) who attended the training and participated in the research by providing services. The staff employed in the study as research officers and investigators contributed significantly through their hard work, and we acknowledge their valuable contribution. We acknowledge the services provided by CORT to enter the data from the nine-month postpartum follow-up of registered women, their husbands, and mothers-in-law in a quick and timely manner. 


\section{BACKGROUND}

The Indian Family Welfare Program, though successful in increasing contraceptive use among couples who have achieved their desired family size, has failed in educating people about the importance and need of using contraceptive methods for spacing births. The concept of interpregnancy spacing and its advantages was never given serious attention as a program objective. The latest National Family Health Survey (NFHS) results show that 77 percent of sterilized women did not use a family planning method before their sterilization (IIPS and Macro International 2007). This information clearly indicates that the concept of spacing has not been promoted and couples, after having children in quick succession, tend to adopt sterilization. In such a situation, it is not surprising that the inter-pregnancy interval has remained short and has deteriorated during the last seven years. Birth intervals of three to five years could increase chances of infant and maternal survival by 2.5 times more than children born at interval of 2 years or fewer (Rutstein 2002; Setty-Venugopal and Upadhyay 2002; Whitworth and Stephenson 2002; Winikoff 1983). Moreover, it is globally recognized that Healthy Timing and Spacing of Pregnancy (HTSP) is an important family planning intervention to improve maternal and child health — the focal points of the Millennium Development Goals (MDGs) 4 and 5.

Research has shown that some of the key factors contributing to the large number of unwanted pregnancies include: (a) programmatic emphasis primarily on women who have achieved their desired family size to motivate them for sterilization, thereby neglecting the education of lowparity couples about contraception and the advantages of spacing; (b) providers find it more time-consuming and challenging to counsel low-parity women on adopting contraception than to counsel women who have achieved their desired family size; (c) lack of access of young women to contraceptive information and services; (d) lack of decision-making power about contraceptive use among young women; (e) pressure from the family members of newly married men and women to attain parenthood as early as possible; (f) lack of effort on the part of the providers to educate pregnant women during Antenatal Care (ANC) about the importance of Postnatal Care (PNC), lactational amenorrhea method (LAM), postpartum contraception, and the advantages of maintaining birth spacing of three years; and (g) the providers' lack of skill in counseling young couples (Khan, Sebastian, and Aeron 2007; Koenig, Foo, and Joshi 2000).

On the positive side, review of literature shows that contraceptive methods offered during the postpartum period are accepted more readily than at other times. Worldwide, 15 to 70 percent of women adopt contraception when offered postpartum (Townsend 2003). The Men in Maternity (MIM) project carried out by the Frontiers in Reproductive Health Program (FRONTIERS) in Delhi showed that counseling during ANC on postpartum contraception and involving men in maternity care significantly increased contraceptive use six months postpartum, as well as the intention among nonusers to do so shortly thereafter (Varkey, Mishra, and Das et al. 2004). Thus while all global, regional, and national studies support the importance and need of maintaining a birth interval of three to five years, the challenge is achieving it. This challenge increases significantly when social constructs act as a barrier and the programmatic environment is insensitive to such desired change. However, if countries wants to achieve MDGs 4 and 5, it is critically important, indeed perhaps a prerequisite, for them to increase utilization of contraceptive methods among young low-parity couples and adoption of postpartum contraception to maintain a birth spacing of three to five years. 


\section{METHODOLOGY}

\section{Objectives}

Keeping the programmatic limitations in view, the FRONTIERS Program, in collaboration with the Department of Health and Family Welfare, Government of Uttar Pradesh (GoUP), the Integrated Child Development Services (ICDS) scheme, the Department of Women and Child Development, GoUP, and the Lala Lajpat Rai Memorial Medical College, Meerut conducted an Operations Research (OR) study to assess the feasibility and effectiveness of using Community Workers (CWs) to promote LAM and postpartum contraception among pregnant women with a parity of zero or one. This study was part of the global effort by the FRONTIERS Program and other service delivery agencies to understand how healthy timing and spacing of pregnancies through increased use of postpartum family planning can be promoted in different settings as a health intervention to reduce maternal and child mortality and morbidities.

The specific objectives of the study were:

1. To understand cultural and reproductive constructs that are conducive for early first birth and short-spaced pregnancies;

2. To develop a comprehensive model and test its effectiveness in educating young couples, elderly family members, and community members about birth spacing and its advantages;

3. To develop and test a model that could increase the use of LAM and postpartum contraception;

4. To use results of the study to create conditions for scaling up the model and encouraging its replication by others.

\section{Research Questions}

Given the time available for the study, it was not possible to measure the intervention's impact on achievement of a birth interval of three to five years. Instead, the study sought to answer the questions as to whether or not the intervention:

- $\quad$ Increased knowledge of the advantages of birth spacing;

- $\quad$ Increased knowledge about LAM and its correct practice;

- Increased use of modern contraceptive methods at nine months postpartum;

- $\quad$ Led to an improved supportive environment, as indicated through support by the mother-in-law and husband for a longer birth interval and use of contraception;

- $\quad$ Shifted counseling by providers from an almost exclusive emphasis on sterilization to counseling on the need for practicing LAM and postpartum contraception.

\section{Study Design}

The study used a quasi-experimental pre- post-test control group design. All pregnant women with a parity of zero or one constituted the study population. Each study group recruited 600 women at three to six months of identified pregnancy. The design is described diagrammatically below. 


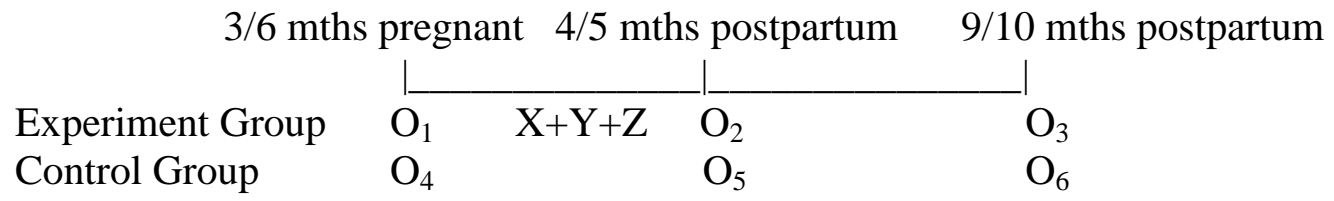

Where

$\mathrm{X}=$ Orientation of all CWs on HTSP, counseling skills, and the importance of promoting postpartum care, LAM, and postpartum contraception

$\mathrm{Y}=$ an educational campaign on HTSP among all pregnant women in the community and the senior women in their family

$\mathrm{Z}=\mathrm{A}$ focused educational campaign on HTSP for husbands and males in the community, with special emphasis on the husband's role in the ANC/PNC of the wife, the use of a condom during pregnancy, LAM, and postpartum contraception

$\mathrm{O}_{1}$ and $\mathrm{O}_{4}=$ Data collected at the time of recruitment of women for the study

$\mathrm{O}_{2}$ and $\mathrm{O}_{5}=$ Information collected at four to five months postpartum

$\mathrm{O}_{3}$ and $\mathrm{O}_{6}=$ Information collected at nine to ten months postpartum.

A sample size of 541women in each group was estimated as sufficient for determining a five percentage point difference between the experimental and control groups in the use of postpartum contraception (Lwanga and Lemeshow 1991). A contraceptive prevalence rate (CPR) of 10 percent among women aged 24 or below was used as the control group prevalence for estimating the necessary sample size (IIPS and ORC Macro 2000). The sample size was increased to 600 to compensate the expected loss by the nine-month postpartum follow-up. The women were interviewed three times (on recruitment (baseline), at four months and at nine months. Their husbands and mothers-in-law were interviewed twice, once at baseline and again at the nine-month postpartum follow-up of the index women. While husbands of all registered women were interviewed, only every third mother-in-law was interviewed. The response rates achieved at each round of interviews was high, as can be seen in Table 1.

Within each PHC, 12 villages having a population of 1,000 or more were selected at random. A census was then carried out of all households in the village to identify all pregnant women. The first 600 women that met the inclusion criteria and agreed to participate in the study were recruited.

Table 1: Response rates

\begin{tabular}{|c|c|c|}
\hline & Experimental & Control \\
\hline Index Women & 605 & 592 \\
Baseline & 554 & 541 \\
4 months postpartum & $92 \%$ & $91 \%$ \\
Response rate & 570 & 560 \\
9 months postpartum & $94 \%$ & $95 \%$ \\
Response rate & & \\
\hline Husbands & 443 & 433 \\
Baseline & 380 & 398 \\
Endline & $86 \%$ & $92 \%$ \\
Response rate & \multicolumn{2}{|c|}{194} \\
Mother-in-law & 198 & 163 \\
Baseline & 158 & $84 \%$ \\
Endline & $80 \%$ & \multicolumn{2}{|c}{} \\
Response rate & \multicolumn{2}{|c|}{} \\
\hline
\end{tabular}




\section{Location of the Study}

The study was carried out in rural areas of the Meerut district, located in the western part of Uttar Pradesh (see map), which has a population of about 2.2 million; 63 percent of the district's population lives in the rural areas. The study covered four Primary Health Center (PHC) areas; two PHC areas were randomly allocated to each study group. Each $\mathrm{PHC}$ had about 40,000 people.

\section{STUDY IMPLEMENTATION}

\section{Preparatory phase}

Three major activities were carried out in the preparatory phase: (a) a formative study and baseline data collection, (b) developing messages and pilot testing IEC materials and counseling aids, and (c) orienting program mangers on the project objectives and procedure.

The purpose of the formative study was to understand the views of all stakeholders-young women, their husbands, elderly family and community members, and the providers-about:

(a) The pressure to have the first child soon after marriage

(b) The perceived importance of maintaining adequate spacing between pregnancies

(c) Reasons why, despite desiring spacing between births, young couples are unable to delay their second pregnancy

(d) The practice of LAM and postpartum contraception.

It was envisaged that the findings of the first phase would be used for developing educational messages and counseling aids that could be used in the second phase to educate different stakeholders (women, husbands, and mothers-in-law) about the need and importance of a birth spacing of three to five years.

Qualitative methods were used to collect this information. A total of 20 Focus Group Discussions (FGDs) and 30 in-depth interviews of newly married and first-time-parent men and women were conducted. In addition, FGDs also were conducted with mothers-in law, community leaders, and family planning providers as follows:

\section{Focus group discussions}

- Women and men who are newly married or first-time parents 6

- Elderly women in the family 4

- Community opinion leaders 2

- Family planning and health care providers 2 


\section{In-depth interviews}

- Newly married (6 months or fewer) non-pregnant women 5

- Newly married (6 months or fewer) pregnant women 5

- Women with one child, delivered in last 6 months 5

- Women with one child, delivered in last 12 to 18 months 5

- Husband of newly married pregnant and non-pregnant women 10

The guidelines for FGDs and in-depth interviews included open-ended questions and probes for issues that may come up during the discussion/interview. These guidelines were written in English and then translated into the local language, Hindi. The vernacular guideline was pretested before data collection began.

Data were collected in July and August 2006. The informants were identified with the help of Auxiliary Nurse and Midwife (ANM) or Anganwadi Workers (AWs). These CWs are generally acquainted with the families, particularly young married couples. ANMs are health and family planning providers at the village level. They are expected to list all pregnant women to ensure that they receive at least three ANC consultations. Under the ICDS, Anganwadi centers are established in all the big villages. An Anganwadi worker is appointed for a population of 1,000 people. These workers, in addition to providing supplementary nutrition to pregnant and lactating mothers and children less than six years of age, have to visit their households to counsel them on health and nutrition.

All the FGDs were taped with the permission of the informants. Similarly, all the informants in the in-depth interviews, except one woman, allowed their individual interviews to be taped. The taped interviews were transcribed and translated within one week of the event. Summaries were written on the day the data were collected. After the in-depth interviews and FGDs were transcribed and translated, a code list was developed using the main themes of the study. The data were coded and analyzed using Atlas-ti, a software package for qualitative data analysis.

Based on the findings of the formative study (described in more detail in Khan, Sebastian, and Aeron 2007), simple, unambiguous messages on the risks of early and short- spaced pregnancies and the benefits of maintaining at least a three-year interval between births were developed. These messages were then incorporated into a series of communications products including:

- Posters: Four types of posters gave key messages about the need for delaying the first birth, spacing three years between births, using LAM correctly, and using contraceptive methods to delay pregnancy.

- Wall paintings: Key messages were painted on walls at important locations like the sub center, PHC, and Panchayat buildings.

- HTSP pocket booklet: A counseling guide for the providers, which also served as an information booklet for the women and their family members, gave information on the advantages of well-spaced pregnancies for the mother, the child, and the family as a whole; how to use LAM correctly; and various contraceptive choices. 
- Leaflets: Leaflets on temporary family planning methods (intrauterine device [IUD], condom, and pills) developed by the State Innovations in Family Planning Services Project Agency (SIFPSA) were distributed in the experimental villages.

All IEC materials and counseling aids were pre-tested for the clarity of the messages, use of words, cultural acceptability, familiarity of the audience with the context, and their relevance for the target audience. The IEC materials also were evaluated by the intended audiences for their layout, use of pictures, typeface, and colors. In consultation with the communication expert, a guideline was developed for pre-testing. The answers obtained for each item of IEC material and counseling aids were analyzed and suitably modified.

The pre-testing was encouraging. Overall, respondents felt that the IEC materials and the booklet were useful sources of information about the importance of birth spacing, delaying first pregnancy, and all contraceptive methods. Many said that they had knowledge about various contraceptive methods but felt that it was the first time that they were being told the importance of birth spacing in such detail. All felt that the information was useful for their husbands and other members of the family as well. About two-thirds of the respondents said that they learned about the need for birth spacing for the first time. Almost all respondents clearly understood the key message in the three stories given in the bookletthe need for delaying the first birth, the financial burden on the husband with closely spaced pregnancies, and the mother-in-law telling her friend about the necessity of spacing between births.

Some of the observations made in the IEC materials, which required modification, included use of certain Hindi words, modification of the picture to depict the use of OCPs clearly and increasing the size of the IUD picture. LAM as a standalone heading in a poster was felt not to be appropriate and it was suggested that the heading state how breastfeeding could protect against the next pregnancy. Most of these concerns were addressed and suggestions were incorporated before printing the materials.

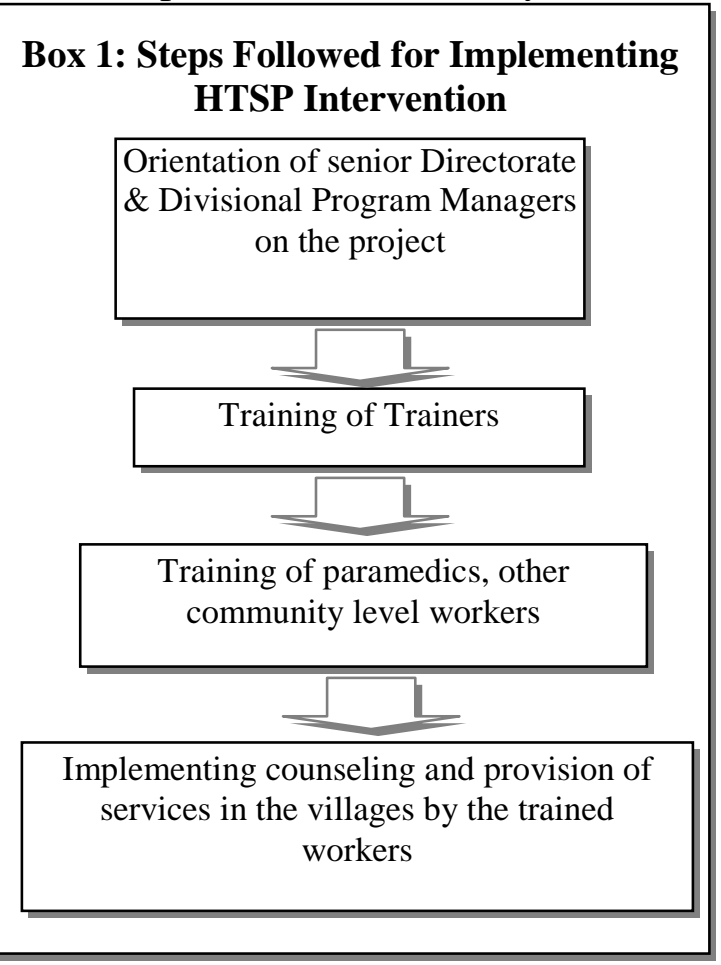

\section{Intervention implementation phase}

The key intervention was an educational campaign on HTSP for pregnant women during ANC visits to the clinics and $\mathrm{CW}$ visits to the home. In addition, their husbands, mothers-in-law and community opinion leaders were also educated. The educational campaign was implemented by 267 CWs who were first reoriented in pre- and postnatal care, LAM, and postpartum contraception and trained in counseling skills to manage young couples' reproductive health needs and use job aids to make their counseling more effective. 
Training of community workers: A three-tier training model was developed, as indicated in Box 1 , to implement the training program. First, a one-day orientation meeting was organized on September 28, 2006, for the medical officers, ICDS officers, and district health and ICDS officers at the medical college, to orient them about the study, its research objectives, and proposed interventions. They were also oriented on how the intervention could help achieve their own program objectives. The orientation meeting was inaugurated by the District Magistrate (DM), who is the chief administrator of the district and all developmental programs, including health programs. His presence in the orientation and support for the intervention gave a clear indication of the commitment of the top program mangers to the proposed program. At the end of the meeting, the participants worked out the training plan for the CWs. The medical officers from the two experimental PHCs and the Child Development Project Officers (CDPOs) from the study areas agreed to train the CWs. The details about how to conduct the training, venue of the training, and the procedure for informing the CWs about the training were discussed in detail and agreed upon.

The training materials were jointly prepared and translated by the FRONTIERS Program staff and the medical college team. The PHC was fixed as the venue for training all paramedics and CWs. Because availability of electricity at the PHC could not be guaranteed, instead of using an overhead projector for training, all teaching materials were written on large (3 ft x $2.5 \mathrm{ft})$ sheets, and those were used as a flipchart during the training. Two sets of such flipcharts were made so that two training classes could be given simultaneously.

At the time of proposal development, training was planned for only health service providersLady Health Visitor (LHV), ANM, Male Health Worker (MHW), and ICDS AWs. However, at the time of implementing the project, a new cadre of community worker, the Accredited Social Health Activist (ASHA), was added in the health system, and for every 1,500 people, one ASHA was appointed. Considering the importance of their presence in the community and their work responsibility, it was decided to also include an ASHA in the training and use both AWs and ASHAs. Table 2 shows the total number of community workers and other health staff who were trained.

Training of the CWs was conducted in groups of 25 trainees over a two day

Table 2: Number of Workers Trained

\begin{tabular}{|l|c|}
\hline \multicolumn{1}{|c|}{ Type of worker } & \multicolumn{1}{|c|}{$\begin{array}{c}\text { Number } \\
\text { trained }\end{array}$} \\
\hline $\begin{array}{l}\text { Chief Medical Officers(CMO), } \\
\text { Deputy CMO }\end{array}$ & 5 \\
\hline DPO, CDPO, supervisors & 5 \\
\hline ANM/LHV & 27 \\
\hline MHW & 15 \\
\hline Anganwadi workers & 117 \\
\hline ASHA & 108 \\
\hline
\end{tabular}
period. A second one-day training was given during the monthly meeting of AWs and ASHAs, one month after the first training. Breaking the training into two parts was necessary because of the difficulty in releasing the workers for three consecutive days of training. In addition, it was felt that the workers may not be able to absorb all the contents of training in one session. The second training was also used for clarifying doubts and questions that the workers might face from their clients during extension work. The training consisted of both classroom and role-play sessions. Role plays by the workers acting as the pregnant women, a CW, and a mother-in-law were not only entertaining but also showed the problems they would face in the households and how they could manage such situations and explain the topics amicably and patiently. The project team was present in all the training sessions and ensured the uniformity of content of the 
training and related explanations. The training was spread over four months (October 2006 to January 2007); because of pulse polio schedules, the workers often were not available.

Inter-sectoral coordination: A key focus of the project was encouraging all community-level workers to work as a team to achieve project objectives, even though they belonged to two different ministries. ANMs, MHWs, and ASHAs are part of the Ministry of Health and Family Welfare, whereas AWs belong to the ICDS program of the Department of Women and Child Development. Even though they are expected to complement each others' efforts, in reality, coordination between the workers of the two departments is minimal. To ensure that such coordination does take place, before starting the project, considerable time was spent in networking with them to explain the objectives of the study and how working as a team at the grassroots level would improve the performance of both programs. These initial efforts helped the district-level officials of both departments jointly worked out a plan in which the CWs could work as a team without affecting their own work. It was decided that an AW and an ASHA would go together to the households of pregnant women and lactating mothers to explain the need and advantages of maintaining a three-year birth interval and adopting postpartum contraception. An ANM from each area worked out a schedule for which day she would be available to talk about these topics in the group meetings that CWs would organize in their work area. Similarly, MHWs were assigned responsibility to conduct group meetings with the husbands of the pregnant women and counsel them individually.

Educational campaign: Each eligible woman was individually visited by the communitylevel workers (AW and ASHA) to explain postpartum care, including LAM and postpartum contraception. All the women were given the HTSP booklet (see Box) with the instruction to share it with her husband and mother-in-law. In addition to pregnant women, older women were invited to attend the group meeting at the Anganwadi center. During the project period, the ANMs also organized and conducted a total of 96 group meetings.

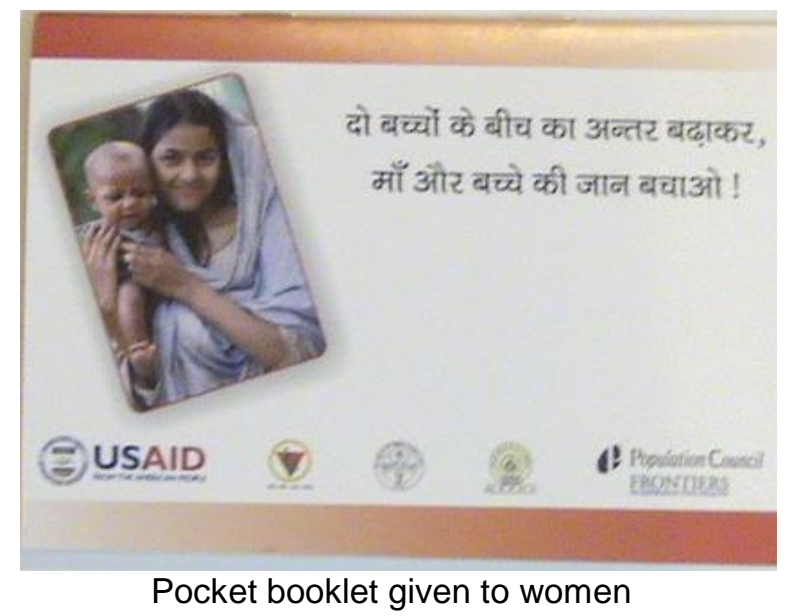

To raise the awareness among husbands, group meetings were organized. In these meetings, in addition to husbands, other community elders and the Pradhan (village leader) were also invited to attend. This approach was to raise the community's awareness about the risks associated with closely spaced pregnancies and why postpartum contraception is important. During the first male group meeting in each of the study villages, the HTSP booklet was made available and they were encouraged to take one. However, availability of MHWs for conducting group meetings remained limited because they had to cover a much larger area than an ANM. This fact, coupled with a lack of enthusiasm in organizing the meetings, led to only three male group meetings being held, out of which only one was managed by an MHW. The remaining two were organized by community-level workers and addressed by an ANM. 
Besides individual consultations with the women and the group meetings of women and men, other IEC materials were disseminated. Four different posters were pasted at the Anganwadi center, the sub-center, the PHC and Panchayat ghar. In addition, the message on the need for spacing and using spacing methods was imparted through wall paintings. Three wall paintings were done in each village at strategic locations where people, especially women, could notice and read the messages. In some villages, the Panchayat ghar's wall was chosen; in others, it was the sub-center's wall or the wall of some prominent community member. Table 3 shows the number of different IEC materials that were distributed among women and men

Table 3: IEC Materials Distributed

\begin{tabular}{|l|c|}
\hline \multicolumn{1}{|c|}{ Type of material distributed } & $\begin{array}{c}\text { Total } \\
\text { dispersed }\end{array}$ \\
\hline Four types of posters & 594 \\
\hline Wall painting & 75 \\
\hline Booklet to women & 1170 \\
\hline Booklet given during first male group meeting & 720 \\
\hline
\end{tabular}
during the project period.

Monitoring: Throughout the project period, monitoring the activities were carried out through three different mechanisms: (a) the regular monitoring procedures of each ministry program; (b) a project-specific monitoring visit by the project staff, and (c) a quarterly review meeting of the Project Management Committee (PMC).

Regular program supervision: An ASHA is supervised and monitored by an ANM, and the AW's activities are monitored by a CDPO. In the initial period of the study, project staff interacted with their supervisors and district-level officials to build their capacity to monitor the project activities, particularly by reviewing the new work register that was introduced by the project. Previously, the work register provided only the number of women who were visited by AWs during the month, with no further information on the topic of counseling or any related issue. To make the extension work of the CWs systematic and help them to cover all the counseling topics, all the workers were given a printed work register developed under the present study. The work registered contained a list of the counseling topics and columns for entering the women's name and date and the date of counseling on each topic. After introducing the new work register, it became easy for the supervisors and project staff (and for the workers themselves) to review whether the community workers were covering all topics, particularly LAM and postpartum contraception, during their house visits to women. The modified work register was highly appreciated by the immediate supervisors and the district-level officials and was recommended by the DM for introduction in other non-project areas also.

Supervisory visits by the project staff: In addition to the regular ministry monitoring systems, project staff visited the villages to check the activities of the CWs. From each Anganwadi area, the project officer randomly selected two women who were registered under the study and two other pregnant women who were not registered under the study. Using a checklist, these four women were asked questions on topics for which information was provided by the community workers. Although workers were told during the training that there would be monitoring visits by the project team, initially many workers did not follow the schedule. Only eight percent of the women were able to mention LAM and birth spacing methods during the first monitoring visit. However, in the subsequent months, there was considerable improvement. The names of Anganwadi workers who did not counsel women were reported to the CDPO who, in turn, 
checked the problems during their monthly meeting. In the experimental area, the study ensured that group meetings of pregnant women and mothers-in-law were held regularly. By April 2007, four months after checking the quality and reach of counseling, 70 percent of the women selected at random were able to correctly discuss LAM and postpartum contraception.

Review meeting by project management committee (PMC): To ensure regular participation and better coordination and support among all the partners, a PMC was formed, with the DM as the chairperson. The medical college team acted as the secretariat and took the initiative to organize a PMC every three to four months. The other members of the PMC were the CMO, Deputy CMOs overseeing the study blocks, the district ICDS officer, the project team from the medical college, and FRONTIERS staff involved in the project.

Originally it was planned to hold the PMC on alternate months. However, because of some practical difficulties and the desire to ensure participation of most of the committee members, the meeting was held every four months. The IEC materials were discussed at the first meeting and finalized for printing. In subsequent meetings, issues related to monitoring were discussed. The DM asked the District Planning Officer (DPO) to print registers for all Anganwadi workers of the district to record the progress of group meetings in all blocks.

The preliminary results from the four- to five-month postpartum follow-up were shared in the next meeting. The positive findings of the results helped in enhancing cooperation between the two departments, and some of the intervention started scaling up in other areas. The transfer of the DM from time to time made it necessary to provide a brief about the project at each meeting.

\section{KEY FINDINGS}

\section{Formative Research}

The data highlighted several important social constructs and pressures that influence young couples' early reproductive life.

Social pressure for first pregnancy: Newly married couples experience huge pressure for an early pregnancy. Findings from the in-depth interviews allude to the circumstances in which women put pressure on their husbands for an early pregnancy or vice versa.

"After marriage I used Nirodh (condom) only for 10 to 12 days. Then my wife started persuading me to have the first child soon. My plan was to have first child after two years, but I had to give in to the pressure from my wife. In fact the pressure was from my grandmother who was all the time telling my wife that she wants to see a grandchild before death." (Husband of newly married pregnant woman, age 20)

"After marriage, I told my husband that I wanted our first pregnancy after one year. But he wanted it sooner. I was upset but then I thought, after all, it is his parents' desire to see their grandchild. So I agreed." (Newly married pregnant woman, age 19) 
Clearly young couples, particularly newly married women, are under heavy pressure from their in-laws and other elder relatives in the family to deliver the first child as soon as possible. Men also face pressure from their family and peer group. A man, married for four months commented:

"I was able to convince my mother that since I am unemployed we will have our first child after two years. My mother agreed. But the way friends tease me is too much to bear. I have managed so far."

Traditional practices: If the woman does not conceive within three to four months after marriage, pressure starts building up and if she does not conceive within 10 to 12 months it becomes a matter of great concern and treatment from a doctor is initiated. Certain Vaidhs (herbal doctors) are popular for their ability in ensuring pregnancy.

"Though we wanted the child soon after marriage, I did not conceive for about a year. My mother-in-law was very concerned and she took me to a doctor. I took the pills he gave me, but nothing happened. So I left him and showed myself to the person who does "Jhaad Phookh" (traditional healer who chants), then too nothing happened. Then I stopped doing anything for some time and I conceived”. (Woman, age 19)

Fear of infertility: Many believe that a contraceptive used to delay the first pregnancy is harmful and could cause infertility. Women narrated experiences where they had to undergo treatment to conceive after discontinuing contraception. Because of the overriding belief that pills cause infertility, women did not use pills before the first child. A young woman during an FGD authoritatively mentioned:

"First of all, people have no information on what to eat (use of FP methods) to avoid pregnancy. I read in the newspaper, so I know that initially one should not use family planning methods as it could cause problem in getting pregnant later."

Providers'biases: The ANMs mentioned that the desire for the first child as soon as possible after marriage is so strong that investing time and energy in counseling newly married couples for contraceptive use is a waste of time. Providers also stated that only those women who face marital conflicts soon after marriage and are not sure whether the relationship will continue, are perhaps the few who would use contraceptives to prevent or delay the first pregnancy. ANMs who are often from the same community share many of the concerns and misconceptions related to delaying the first pregnancy. For instance, some of the providers also felt that contraceptive use to delay the first pregnancy is harmful and could cause infertility. A typical quote expressing their view:

"Some risk is involved in delaying first pregnancy for one or two years. It may be difficult for them to conceive later."

Reasons for not spacing births: Both men and women desired the second child three or more years after the birth of first child. The advantages of spacing between the first and second child appealed to all, including husbands and mothers-in-law. Spacing births for more than three years 
was seen to be advantageous for all - mother, child, and husband. Women agreed that birth spacing for three years would ensure that children are well fed and well cared for. They also said that closely spaced births made women weak and in turn affected the health of the child in the womb. As one young woman mentioned:

"Everyone knows if children are closely spaced there will be problems. We know it makes women weak and children will fall sick frequently."

Husbands wanted their wives to be healthy because their illness can be financially draining:

"If the woman is sick, the whole house comes to a standstill. We are laborers. Money is hard to earn and we don't want anyone to fall ill." (FGD of husbands)

Despite young men and women desiring a second child after a minimum of three years, they generally fail to maintain this inter-pregnancy interval. Besides the programmatic failure to help young couples delay their second child, cultural constraints work as bottlenecks to realizing their desired birth interval.

Lack of knowledge of return to fertility and use of contraceptive methods: Lack of knowledge about when women would return to fertility after delivery, coupled with insufficient information about contraceptive methods, turned out to be the major causes for the resultant unwanted pregnancies. When women were informed about the possibility of getting pregnant as early as four to six weeks after delivery, they were surprised and wanted to know when to start contraception after delivery and appropriate contraceptive methods. Besides a lack of information, inaccurate information was causing many unwanted pregnancies. Discussions with young women indicated that they considered return of menstruation as the only sign of return of fertility:

"It is all about menstruation. When you get menstruation after delivery, you can get pregnant."

Some women wondered how someone they know had conceived before menstruation began after delivery. Clearly they had no idea that 40 days after delivery fecundity could return at any time:

"My neighbor did not even get her menses after delivery. Two months later she realized she was pregnant again. Her children look like twins; not even a year's difference between them."

Lack of knowledge on LAM: Women did not know the role of breastfeeding in delaying the next child. Some believed that as long as a woman is breastfeeding, menstruation will not return and she will not conceive again. Women did not know about LAM - less than three percent of the women interviewed knew all three conditions that have to be fulfilled for breastfeeding to be effective in preventing next pregnancy for six months (the woman is fully breastfeeding, her menstruation has not returned, and her child is less than six months old). A first-time pregnant woman said:

"People say, as long as the mother is breastfeeding, she will not conceive. Is this right?" 
When asked about "conditions required for preventing pregnancy by breastfeeding, a currently pregnant woman who conceived four months postpartum said:

"No conditions. Just breastfeeding is enough. For me it worked for four months. (She started menstruation after one month.)

Only one of the men whose wife had a three-month old baby was able to state the three conditions of LAM. He learned these from the radio.

Poor service provision and counseling: Most of the ANMs do not routinely counsel women on postpartum contraception or LAM during their ANC visits. Discussions on postpartum care or visiting women during the first week after delivery are also rare - less than 10 percent of the women surveyed had been educated about LAM or postpartum contraception by the health providers or AWs. A woman three months postpartum said:

"It's two years since we have been living here. No one has come for counseling. During pregnancy, the Anganwadi worker told me to go to the ANM and get my TT injection. I got the injection and the ANM gave me some pills to eat. Nothing was said about contraceptive methods, breastfeeding or any other care."

A husband said:

"Nobody came for a postpartum check-up or counseled us about family planning. No one visited us when she was pregnant, nor after she delivered. Only once, the ANM came to check if we had taken the child for pulse polio."

Counseling for using contraceptives after delivery was lacking for the young women going through different phases of pregnancy and postpartum. After miscarriage, the only advice one woman received was:

"Don't try for the next pregnancy soon. Wait for four to five months at least before getting pregnant again. Nothing was said about how to avoid a pregnancy for four months."

Myths and misconceptions about birth spacing methods: Many misconceptions and myths are attached to each birth spacing method. This situation, in turn, results in low contraceptive use among young couples. For example, apart from the general complaint of lack of sexual pleasure, many (particularly women) believe that a condom could cause an infection leading to stoppage of the menstrual cycle.

Although some of the young informants had seen information about contraceptive methods on $\mathrm{TV}$, correct knowledge was lacking. One of the informants, who had seen an AIDS awareness poster promoting use of condoms to protect against infection, misunderstood the message and believed that condoms will cause infection. In her words: 
"My husband has said that we will use a condom after the baby is born. I have refused it point blank. I don't want to get any infection."

Erosion of cultural practices: During the discussions, a few changes in cultural practices were also mentioned as causes for a short birth interval. For example, elderly women reported that when they were young, women maintained a much longer period of abstinence after delivery, both voluntarily and involuntarily because most women used to travel to their parents' home to deliver their first child and then stayed there for a long period. In some cases, such abstinence was for more than one year. Even when they returned to the in-laws, the husband maintained some abstinence voluntarily, particularly if the woman was still breastfeeding. There is a belief that sexual intercourse during the time a woman is breastfeeding can spoil the milk and thus affect the health of the baby. These traditional practices are vanishing fast. Most women do not go to their parents' home for delivery, postpartum abstinence has been reduced to a few weeks, and most couples become sexually active after about 40 days. Because these traditional practices are disappearing fast and family planning is not practiced, the birth interval has shortened. This point was mentioned by many elderly informants:

"Earlier, a two to three year gap between children was natural and happening on its own. After childbirth, for two years, the mother-in-law would ask them to remain at the home. These days, no husbands want to abstain. Now they say, once married this is your house, so you stay here only." (Elderly woman, FGD)

A woman with two children mentioned:

"We did not have sex after my delivery for some time, but when he saw that I have started doing household chores, he started having sex."

\section{Quantitative Survey Findings}

\section{Profile of women, husbands, and mothers-in-law}

The Appendix provides the background characteristics of the respondents. A total of 1,197 pregnant women, 922 husbands, and 407 mothers-in-law were interviewed at baseline. Of these, 605 pregnant women, 471 husbands, and 198 mothers-in-law were from the experimental areas, and 592 pregnant women, 483 husbands, and 209 mothers-in-law were from the control areas.

The majority of women in both the experimental and control areas were in the 20 to 24-year age group. The mean age at the time of cohabitation was reported to be 19.3 years. The majority $(81 \%)$ was Hindus. Among the Hindus, scheduled caste, other backward castes, and high-caste Hindus were almost equally distributed. Very few (about 3\%) were scheduled tribes. The majority of women were literate and almost all (98\%) were not working for pay. About twothirds of the women were pregnant for the first time. Comparison of the experimental and control groups showed that their background characteristics were similar.

Only ten percent of the husbands were illiterate; about one third had completed grade 9 or 10. Twenty-four percent of the men were engaged in work in their own agriculture fields. A higher 
proportion of men in the control area (30\%) worked as unskilled labor compared with the experimental area $(19 \%)$.

The background characteristics of mothers-in-law showed that about one in five were widowed and a small proportion was separated or divorced. Most were in the 40 to 60 -year age bracket.

\section{Exposure to the educational campaign}

Women from the experimental group were asked whether they had received the HTSP booklet, saw posters and wall paintings, or participated in any group meeting organized by the community workers. As seen in Table 4, the educational campaign was successful in exposing most of the women to the IEC messages on HTSP. Nine out of ten of those who received the booklet showed it to their husbands, but only about half of the young women shared the booklet with their mother-in-law. This indicates the social distance between mothers-in-law and their daughters-in-law and their hesitation in discussing reproductive health matters with senior family members. About one third of the women had seen at least one poster on birth spacing, and 30 percent had read HTSP messages painted on the walls of the Anganwadi center or other prominent places. Forty-five percent of the women had seen at least one of the messages on birth spacing disseminated through posters and wall paintings.

\section{Counseling efforts by community workers}

Significantly more women in the experimental area reported receiving counseling by community workers on a range of topics (see Figure 1 below). Discussions of LAM, STIs and HIV/AIDS increased substantially in the experimental area but there were no changes in the control areas, indicating that the training for community workers in these topics did influence the way they carried out their counseling activities.

For messages concerning delaying first birth using FP, having a postpartum check-up within the first week after delivery, and birth spacing methods, there were substantial and significant increases in both the experimental and control groups. While the increases in the experimental groups can be attributed to the training of the community workers, the significant increases in the control group are probably the result of some contamination through supervision. The DPO supervised community workers in both experimental and control areas and was also a member of the PMC. It appears that during the monthly supervisory meetings she and another senior staff member may have advised the community workers in the control areas to follow the same work pattern as those in the experimental areas, and placed emphasis on them discussing these issues concerning family planning and birth spacing. 
Figure 1: Topics Covered by Community Workers during House Visits

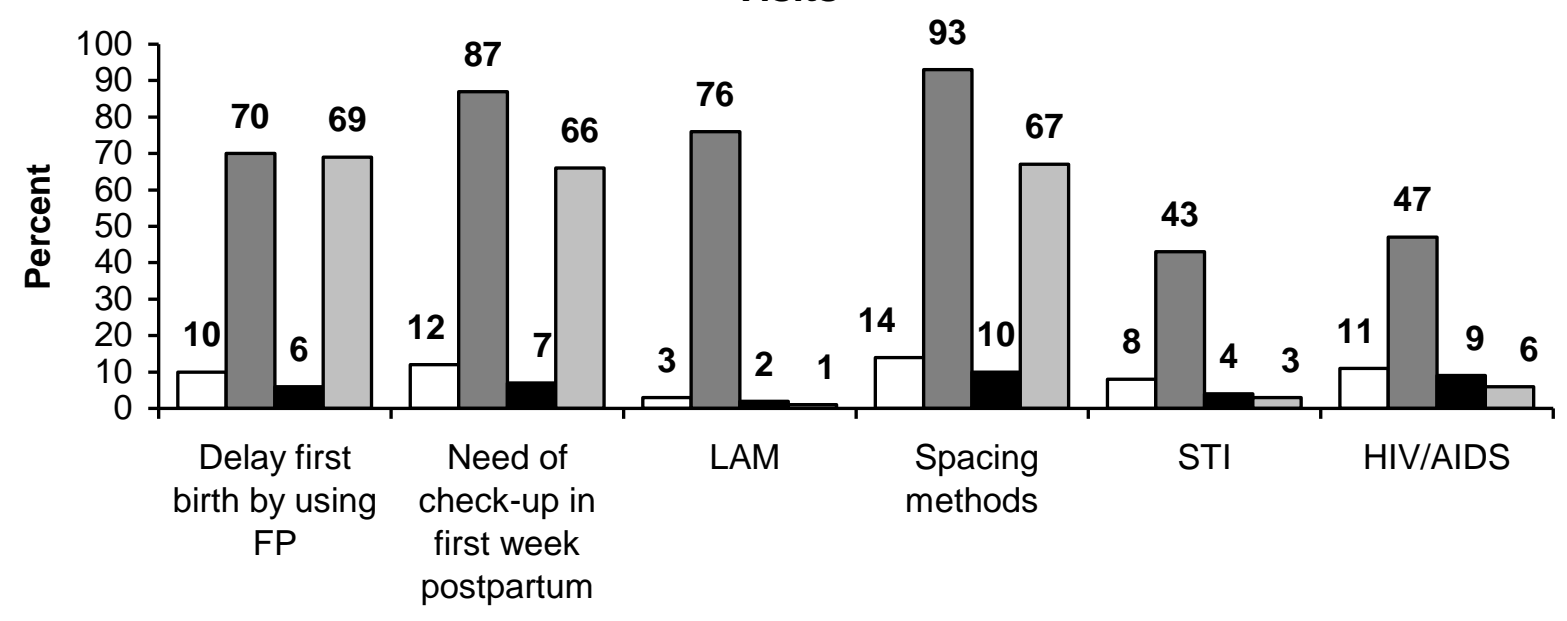

$\square$ Experimental Baseline $\square$ Experimental Follow-up $\square$ Control Baseline $\square$ Control Follow-up

\section{Effect on supportive environment}

One reason for involving husbands and mothers-in-law in the intervention was to increase their support for a longer birth interval and the use of modern contraceptives to delay pregnancy. Information gathered from husbands and mothers-in-law indicated that there were significant increases in the experimental group in their awareness of the need for birth spacing and in knowledge of spacing methods compared to the baseline; moreover, at nine months postpartum, knowledge of birth spacing methods was also higher compared with the control group.

Approximately half of the husbands in both groups reported accompanying their wives for ANC visits. The main reason given for not accompanying the wife was that they had to look for work $(39 \%$ in the experimental area and $49 \%$ in the control area), followed by the fact that the mother-in-law is expected to take care of women at home (about $17 \%$ in both groups).

Although an equally high proportion of husbands and wives in both groups discussed when to have the next child (see Table 5), a significantly higher proportion in the experimental than in the control group reported discussing family planning
Table 5: Proportions discussing about Spacing and Family Planning (Percentages)

\begin{tabular}{|l|c|c|}
\hline & Experimental & Control \\
\hline $\begin{array}{l}\text { Husband-wife } \\
\text { discussed when to } \\
\text { have next child }\end{array}$ & $85(\mathrm{n}=560)$ & $85(\mathrm{n}=570)$ \\
\hline $\begin{array}{l}\text { Husband-wife } \\
\text { discussed family } \\
\text { planning methods }\end{array}$ & $61(\mathrm{n}=560)^{* * *}$ & $39(\mathrm{n}=570)$ \\
\hline $\begin{array}{l}\text { Mother-in-law and } \\
\text { daughter-in-law } \\
\text { discussed timing of } \\
\text { next pregnancy }\end{array}$ & $20(\mathrm{n}=144)$ & $23(\mathrm{n}=152)$ \\
\hline $\begin{array}{l}\text { Mother-in-law and } \\
\text { daughter-in-law } \\
\text { discussed family } \\
\text { planning methods }\end{array}$ & $5(\mathrm{n}=144)$ & $5(\mathrm{n}=152)$ \\
\hline \begin{tabular}{l}
$\mathrm{z}$ test, experimental vs. control: $* * \mathrm{p} \leq 0.001$ \\
\hline
\end{tabular}
\end{tabular}


methods. As is evident in Table 5 also, there is a general lack of communication between women and their mother-in-law. This is also supported by the finding that although 88 percent of the women who received the HTSP booklet shared it with their husbands, only 49 percent shared it with their mother-in-law (although nine percent of these were either because the mother-in-law was not alive or was not staying with them).

\section{Knowledge of birth spacing methods}

Figure 2 compares women's knowledge in experimental and control areas at nine months with their knowledge at baseline (the baseline data showed no difference between the two groups and so has been combined here for ease of presentation). Correct knowledge among women in the experimental areas increased significantly for all methods, especially for IUD and emergency contraception (although this remained extremely low at less than 20 percent). Correct knowledge of the use of OCPs increased significantly in both experimental and control areas, although the increase was greater in the experimental area; again, this may have been due to the contamination through supervision mentioned earlier. Correct knowledge on condom use was already high before the intervention and the increase was not significant.

\section{Figure 2: Knowledge of Spacing Methods and Emergency} Contraception

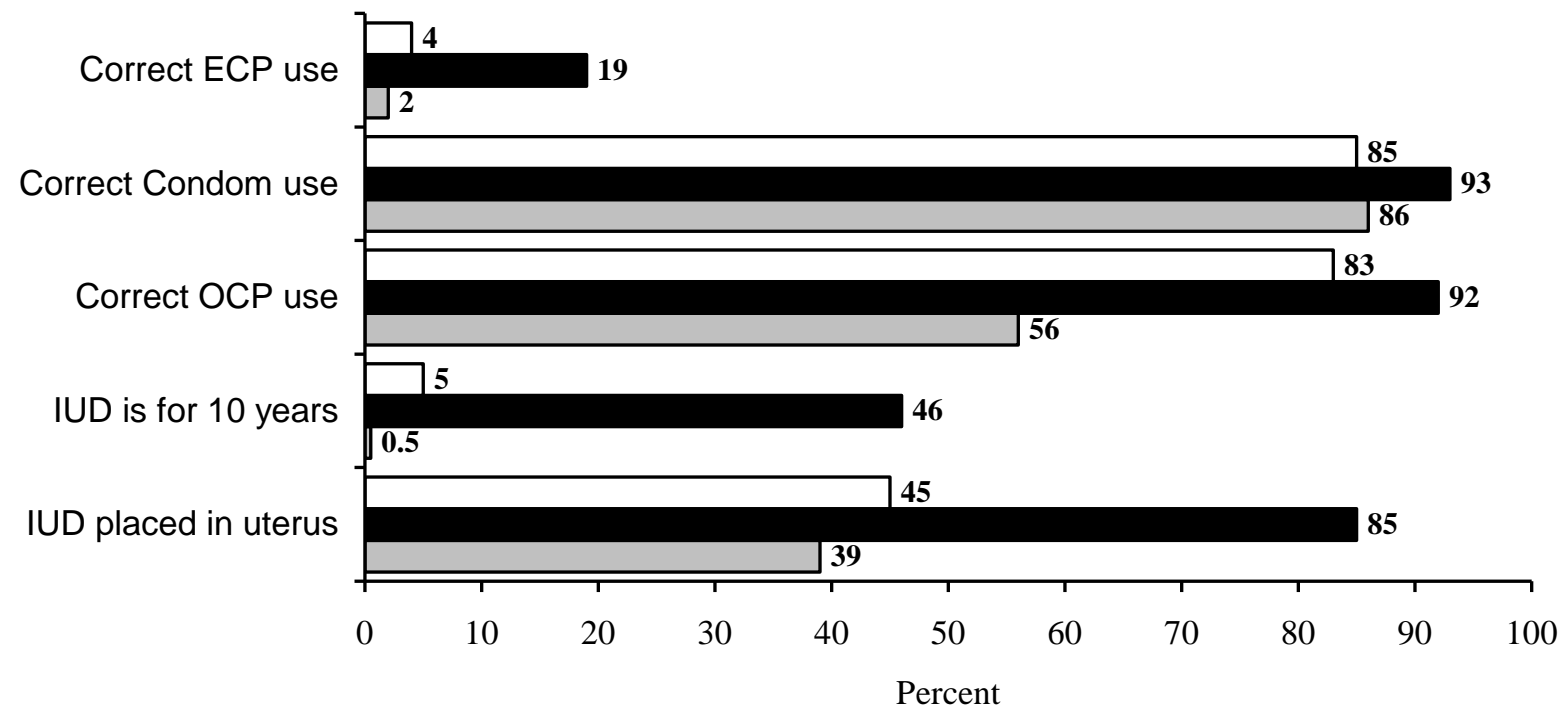

Baseline (n=1197) Experimental Follow-up(n=570) $\square$ Control Follow-up (n=560)

\section{Postpartum contraceptive use}

At baseline, none of the women in either the experimental or control groups could describe the three conditions for practicing LAM. During the follow-up interviews at 4-5 months postpartum, 78 percent of women in the experimental group but less than one percent in the control group could state these conditions. Based on their responses, almost one quarter $(23 \%)$ of women in the experimental group reported using LAM at this time to prevent pregnancy, whereas no women in 
the control group reported using LAM. However, 16 percent of women in the control group satisfied the three conditions and so were protected by LAM but without intentionally practicing the method.

At nine months postpartum, 68 percent of those women in the experimental group who reported using LAM for pregnancy prevention at 4-5 months had shifted to using a contraceptive method. Of those not using contraception, five percent wanted to get pregnant, fifteen percent reported that their menses had not returned ort that they felt they couldn't conceive, ten percent gave no reason, and the remaining four percent gave other reasons.

As Table 6 indicates, by the nine-month follow-up interview about twice as many women in the experimental areas than in the control areas were practicing contraception. Most women in both groups were using condoms and pills. Moreover, significantly less women were pregnant in the experimental area $(10 \%)$ compared with the control area (16\%). Approximately ten percent of the women in both areas wanted to be pregnant soon because of the death of the previous child. Probing for the reason for the

Table 6: Contraceptive Use at Nine Months Postpartum (Percentages)

\begin{tabular}{|l|c|c|}
\hline & $\begin{array}{c}\text { Expt. } \\
(\mathbf{n}=\mathbf{5 7 0})\end{array}$ & $\begin{array}{c}\text { Control } \\
(\mathbf{n}=560)\end{array}$ \\
\hline Currently using FP & $63^{\star * *}$ & 32 \\
Condom & 44 & 23 \\
Pills & 15 & 7 \\
IUD & 2 & 0.2 \\
Sterilization & 1 & 1 \\
Traditional & 1 & 1 \\
\hline Currently not using FP & 27 & 52 \\
\hline Currently pregnant & $10^{* *}$ & 16 \\
\hline${ }^{* *} \mathrm{p} \leq 0.01,{ }^{* * *} \mathrm{p} \leq 0.001$ & \multicolumn{2}{|l}{}
\end{tabular}
pregnancy found that in 53 percent of the cases in the experimental area and 20 percent of those in the control area the pregnancy was due to contraceptive failure (primarily the condom).

Logistic regression analysis was employed to estimate the influence of background characteristics and intervention components on postpartum contraceptive use. The variables considered exogenous to contraceptive use that were included in the regression equation were level of schooling of the woman, whether the index child is alive, knowledge of spacing methods, husband-wife communication on spacing and family planning, and the number of topics for which women received counseling. Different models were formed to understand the determinants of contraceptive use. Model 1 used the type of area (intervention/control area), level of schooling, knowledge of spacing methods, and husband-wife communication. Model 2, in addition to the above, included the number of topics counseled by the community workers. Model 3 looked at the impact of exogenous variables if the effect of being in the experimental or control area is removed from the equation.

Table 7 shows that the odds of using contraception at nine months postpartum was 1.6 times greater if the woman lived in the experimental area (Model 1). Earlier research has shown that education has a positive influence on contraceptive use and the results of all three models reconfirm this - the higher the education, the higher the odds of using a contraceptive method. Similarly, the first two models show that if the index child survives, acceptance of postpartum contraception will be 2.25 times more than when the child does not survive. 
Table 7: Logistic Regression Analysis Assessing Factors Contributing to Postpartum Contraceptive Use (odds ratios)

\begin{tabular}{|c|c|c|c|}
\hline Variable & Model 1 & Model 2 & Model 3 \\
\hline $\begin{array}{l}\text { Type of Area } \\
\text { Control area (ref) } \\
\text { Experimental area }\end{array}$ & $\begin{array}{l}0 \\
1.631^{* * *}\end{array}$ & $\begin{array}{l}0 \\
1.385\end{array}$ & --- \\
\hline $\begin{array}{l}\text { Education } \\
\text { Illiterate (ref) } \\
\text { Read and write, Class 1-5 } \\
\text { Class 6-10 } \\
\text { Class 11+ }\end{array}$ & $\begin{array}{l}0 \\
1.518^{\star} \\
1.704^{\star \star} \\
1.944^{\star \star *}\end{array}$ & $\begin{array}{l}0 \\
1.524^{*} \\
1.74^{\star *} \\
1.873^{\star * *}\end{array}$ & $\begin{array}{l}0 \\
1.081 \\
1.256 \\
1.526^{*}\end{array}$ \\
\hline $\begin{array}{l}\text { Index child died/still birth/miscarriage (ref) } \\
\text { Child alive }\end{array}$ & $\begin{array}{l}0 \\
2.273^{\star * *}\end{array}$ & $\begin{array}{l}0 \\
2.292^{* * *}\end{array}$ & $\begin{array}{ll}0 \\
0.821\end{array}$ \\
\hline $\begin{array}{l}\text { Knowledge of spacing methods } \\
\text { Mentioned zero (ref) } \\
\text { Mentioned one } \\
\text { Mentioned two } \\
\text { Mentioned three or four }\end{array}$ & $\begin{array}{l}0 \\
1.381 \\
1.311 \\
1.318\end{array}$ & $\begin{array}{l}0 \\
1.332 \\
1.215 \\
1.247\end{array}$ & $\begin{array}{l}0 \\
1.235^{\star * *} \\
1.244^{* * *} \\
1.272^{* * *}\end{array}$ \\
\hline $\begin{array}{l}\text { Number of topics counseled on } \\
\text { None (ref) } \\
\text { One } \\
\text { Two } \\
\text { Three } \\
\text { Four } \\
\text { Five } \\
\text { Six }\end{array}$ & --- & $\begin{array}{l}0 \\
1.540 \\
1.800^{\star} \\
1.570 \\
1.522 \\
1.753 \\
2.268^{\star *}\end{array}$ & $\begin{array}{l}0 \\
0.523^{\star} \\
0.750 \\
0.687 \\
0.834 \\
1.132 \\
1.256\end{array}$ \\
\hline $\begin{array}{l}\text { Husband-wife communication } \\
\text { No discussion (ref) } \\
\text { Discussed when to have next child } \\
\text { Discussed family planning method use } \\
\text { Discussed both of the above }\end{array}$ & $\begin{array}{l}0 \\
0.550^{* *} \\
7.806^{* *} \\
4.235^{\star * *}\end{array}$ & $\begin{array}{l}0 \\
0.482^{\star * *} \\
6.743^{\star *} \\
3.888^{\star * *}\end{array}$ & $\begin{array}{l}0 \\
0.550^{\star *} \\
7.807^{\star *} \\
4.235^{\star * *}\end{array}$ \\
\hline
\end{tabular}

${ }^{*} p \leq 0.05,{ }^{* *} p \leq 0.01,{ }^{* * *} p \leq 0.001$

Husband-wife communication on fertility issues, such as birth spacing and family planning methods, significantly increased acceptance of postpartum contraception - for example, the odds ratio when the couple talked about family planning, ranged from 6.7 to 7.8 times greater than when they did not.

When the number of topics for which women received counseling was included in the equation (Model 2), living in the experimental area stopped being significant. However, the effect of counseling on contraceptive use emerged as being significant. Evidently, the impact of intervention has an interactive effect on the type of area.

To further curb the compounding effect of type of area, it was removed from Model 3, keeping the other variables in Model 2 the same. The effect of education and topics counseled regarding contraceptive use diminished in this model, while the effect of the knowledge of birth spacing methods emerged highly significant. Seventy-five percent of the women from the experimental area and 47 percent from the control area could mention all three birth-spacing methods provided at the PHCs $(\mathrm{z}=9.98, \mathrm{p} \leq 0.001)$. This does indicate the possibility of an interaction between the level of education and the level of counseling on birth spacing methods. 
The findings of three models taken together show that the intervention worked well and through increased counseling, led to better knowledge of family planning methods for spacing, the advantage of postpartum contraception, and better husband-wife communication on family planning. The HTSP booklet acted as catalyst and cue to husband-wife communication. Besides these, parameters not influenced by the intervention, such as education of the women and survival of the index child also had direct bearing on postpartum contraception.

Despite the increase in knowledge about spacing methods among women and their husbands, many couples did not adopt a method because the wife had not started menstruation. Input from the in-depth interviews with postpartum women and husbands indicated reasons for not using contraception such as:

"After the baby was born, I used pills for some time and the condom too. Then my husband stopped me from using any family planning method. He did not like using a condom, and he did not want me to use pills. (Prompt: What about the IUD?) I have heard that the IUD causes too much bleeding and makes us weak. Definitely, I am scared of getting pregnant anytime." (Female, nonuser)

"The point is she won't conceive before the baby is one to one and one half years old. Sometimes women will not get menses for four to five years. When menstruation starts, we need to be careful when we are having sex. To prevent pregnancy, don't have sex for 15 days after menstruation and next 15 days are safe." (Male, nonuser)

The in-depth interviews also showed other areas that needed further explanation to help couples to better understand birth spacing. For example, a woman who had a cesarean delivery and was told by the doctor not to have another child for three years had not understood that the doctor was talking to her about birth spacing:

"Doctor told me not to have another child for three years, I think because some complication could develop from the operation". 


\section{DISSEMINATION AND UTILIZATION OF THE RESULTS}

The study was designed recognizing the need to give greater importance to promoting spacing between births and use of spacing methods within the government program if MDGs 4 and 5 are to be attained. The study and the tools developed received much attention from the district-level partners and the MoH\&FW. Noticing the impact of the intervention, the DM decided to scale up the training and monitoring model to the other blocks and non-intervention villages in the experimental blocks and

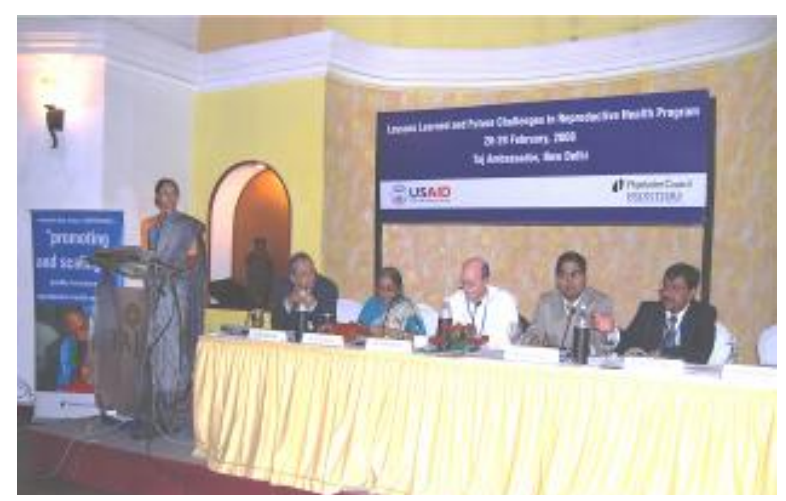

Presentation of the study findings at FRONTIERS Dissemination Meeting, 2008 requested that the Population Council provide technical assistance in scaling-up the intervention. Because of other priorities, this has not yet reached the planning stage.

The study findings have been presented at various national and international forums, including:

Findings of the formative research were presented at:

- Population Association of America, New York - March 29-31, 2007

- USAID, Washington, DC (Brown bag) - April 2, 2007

Four months postpartum follow-up results were presented at:

- Extending Services Delivery Project, Washington, DC (Brown bag) - November 2007

- Scaling-up high-impact FP/MNCH best practices: Asia and Near East Technical meeting, Bangkok - September 3 - 8, 2007

- Asia Pacific Conference on Reproductive and Sexual Health, Hyderabad October 29-31, 2007

Final results, including nine months postpartum follow-up results, were presented at:

- $\quad$ FRONTIERS End of Project meeting, Delhi - March 28-29, 2008

- USAID Asia Bureau SOTA meeting, Bangkok - March 3-6, 2008

- FRONTIERS End of Project meeting, Cairo, Egypt - March 24, 2008

- "Strengthening Family Planning Services through Operations Research: Lessons Learned and Future Directions," Washington, DC - April 23-24, 2008

- State-level FRONTIERS End of Project meetings at Dehradun and Ahmedabad, India - April 10 and May 15, 2008.

Research updates and OR summaries also became sources of disseminating the study findings. The findings from the formative research were printed as the first research update on the study. The second update discussed, in detail, the training, intervention, and the study findings. A twopage summary of the study was circulated during the different meetings, along with the presentation. 


\section{DISCUSSION}

This study was undertaken to test a comprehensive Behavior Change Communication (BCC) model for its effectiveness in educating young couples and family and community members about healthy timing of birth spacing and the use of LAM and postpartum contraception to increase the interval between pregnancies. Findings clearly showed the need for such an intervention and that that it can increase use of LAM and postpartum contraception. The intervention, comprising a one-day orientation and planning meeting with district officials followed by two days' training of paramedics and other community workers, was shown to be feasible and effective in enhancing the skills and improving counseling and services given to young couples. The lessons learned are as follows:

1. The study clearly demonstrated that the model developed and tested to promote LAM and postpartum contraception among young couples to increase the inter-pregnancy interval is successful and could be replicated and scaled up fairly easily. The strength of the model is that it was implemented through existing public sector community-level workers.

2. The study confirmed that young couples want to keep a three to five-year interval between births. The high use of contraception at nine to ten months postpartum $(68 \%)$ in the experimental area shows that couples who are provided with the correct information and contraceptive services will adopt LAM and then transition from LAM to modern contraceptive methods. These outcomes can be achieved by the community workers; the paramedics (ANM and LHV) who have to cover a much larger population are not the best choice for such an educational campaign and their role should be confined to being resource persons, providing supportive supervision to the CWs (ASHA and Anganwadi workers), and addressing group meetings organized by CWs.

3. The study showed that families accept the advice of community workers more readily if counseling for postpartum contraception is done in the broader framework of increasing the inter-pregnancy interval, linking the interval to the health of the mother and child health and to the overall financial and emotional benefits for the couples and family, rather than counseling only for family planning or sterilization. To achieve this, the community workers need to be specially trained in the skills needed for counseling young couples and should be provided with proper educational and counseling aids.

4. In the context of India, the study demonstrates that cooperation between workers of two different departments, the Anganwadi workers (ICDS) and the ASHA/ANM $(\mathrm{MOH} \& \mathrm{FW})$ is feasible and that the synergistic impact of working together as a team benefits both programs. The willingness of the district-level officials and their desire to cooperate with each other made this study successful. For them, it is important to understand the dynamics of how promotion of LAM and postpartum contraception to increase the birth interval could help in achieving their respective program objectives. 
5. It is important that the community workers and their immediate supervisors get a clear signal that the system and senior program managers are committed to the intervention. For example, even a minor involvement (e.g., chairperson of the project management committee) of the District Magistrate, who by virtue of his position is in charge of all development activities in the district, made a big difference in bringing the desired cooperation between the two departments and their community-level workers. His involvement at the initial stage of the program is desirable to ensure commitment of the whole governmental system.

6. The IEC materials, counseling aids, and work registers for the community-level workers developed for this project were found to be highly effective and useful tools. These materials could be adopted in replicating and scaling up the model. 


\section{REFERENCES}

International Institute for Population Sciences (IIPS) and ORC Macro. 2000. National Family Health Survey (NFHS-2), 1997-98: India. Mumbai: IIPS.

International Institute for Population Sciences (IIPS) and Macro International. 2007. National Family Health Survey (NFHS-3), 2005-06: India:Volume1. Mumbai: IIPS.

Khan, M.E. and C.V.S. Prasad. 1990. Third All India Family Planning Survey. Monograph. Baroda: Operations Research Group.

Khan, M.E., M.P. Sebastian, and A. Aeron. 2007. "Promoting Healthy Timing and Spacing of Pregnancy: Barriers and Possible Intervention - Observation from a Qualitative Study in Uttar Pradesh.” Research Update No. 13. New Delhi: Population Council/FRONTIERS.

Khan, M.E., M.P. Sebastian, R. Idnani, and K. Kaushal. 2008. "Promoting Postpartum Contraception among Young Low Parity Women: Some Salient Findings." Research Update No. 14. New Delhi: Population Council/FRONTIERS.

Koenig, M.A., G.H.C. Foo, and K. Joshi. 2000. "Quality of Care within the Indian Family Welfare Programme: A Review of Recent Evidence." Studies in Family Planning, vol. 31(1): 1-18.

Lwanga, S. K. and S. Lemeshow. 1991. Sample Size Determination in Health Studies: A Practical Manual. Geneva: World Health Organization.

Rutstein, S. 2002. "Relationships between pregnancy intervals and prenatal mortality." Proceedings of the 2 nd Champions meeting on birth spacing. Washington, DC, May 2, 2002. CATALYST Consortium, pp. 15-22.

Setty-Venugopal V. and U.D. Upadhyay. 2002. "Birth Spacing: Three to Five Saves Lives." Population Reports, Series L, No. 13. Baltimore: Johns Hopkins Bloomberg School of Public Health, Population Information Program, Summer.

Townsend, J. 2003. "Evidence-Based Programming for Birth Spacing." PowerPoint presentation made at the Fourth Champions meeting on Optimal Birth Spacing. Washington DC, September 2, 2003.

Varkey, Leila Caleb, Anurag Mishra, Anjana Das, et al. 2004. "Involving Men in Maternity Care in India." Final Report. New Delhi: Population Council/FRONTIERS.

Whitworth, A. and R. Stephenson. 2002. "Birth spacing, sibling rivalry, and child mortality in India.” Social Science and Medicine 55(12): 2107-2119.

Winikoff, B. 1983. "The effects of birth spacing on child and maternal health." Studies in Family Planning 14(10): 231-245. 


\section{APPENDIXES}

\begin{tabular}{|l|c|c|c|c|c|c|}
\hline \multicolumn{7}{|l|}{ Table 1: Coverage of Study (Experimental Blocks and Control Blocks) } \\
\hline \multirow{2}{*}{ Name of Blocks } & \multicolumn{2}{|c|}{ Index Women } & \multicolumn{2}{c|}{ Husband } & \multicolumn{2}{c|}{ Mother-in-law } \\
\cline { 2 - 7 } & $\mathbf{N}$ & $\%$ & $\mathbf{n}$ & $\%$ & $\mathbf{n}$ & $\%$ \\
\hline Experimental & & & & & & \\
\hline Sardhana & 373 & 62.0 & 277 & 62.5 & 109 & 55.0 \\
\hline Daurala & 232 & 38.0 & 166 & 37.5 & 89 & 45.0 \\
\hline Total & $\mathbf{6 0 5}$ & $\mathbf{1 0 0 . 0}$ & $\mathbf{4 4 3}$ & $\mathbf{1 0 0 . 0}$ & $\mathbf{1 9 8}$ & $\mathbf{1 0 0 . 0}$ \\
\hline Control & & & & & & \\
\hline Mawana & 293 & 49.0 & 215 & 49.6 & 103 & 53.1 \\
\hline Hastinapur & 299 & 51.0 & 218 & 50.4 & 91 & 46.9 \\
\hline Total & $\mathbf{5 9 2}$ & $\mathbf{1 0 0 . 0}$ & $\mathbf{4 3 3}$ & $\mathbf{1 0 0 . 0}$ & $\mathbf{1 9 4}$ & $\mathbf{1 0 0 . 0}$ \\
\hline Total Sample & $\mathbf{1 1 9 7}$ & & $\mathbf{8 7 6}$ & & $\mathbf{3 9 2}$ & \\
\hline
\end{tabular}

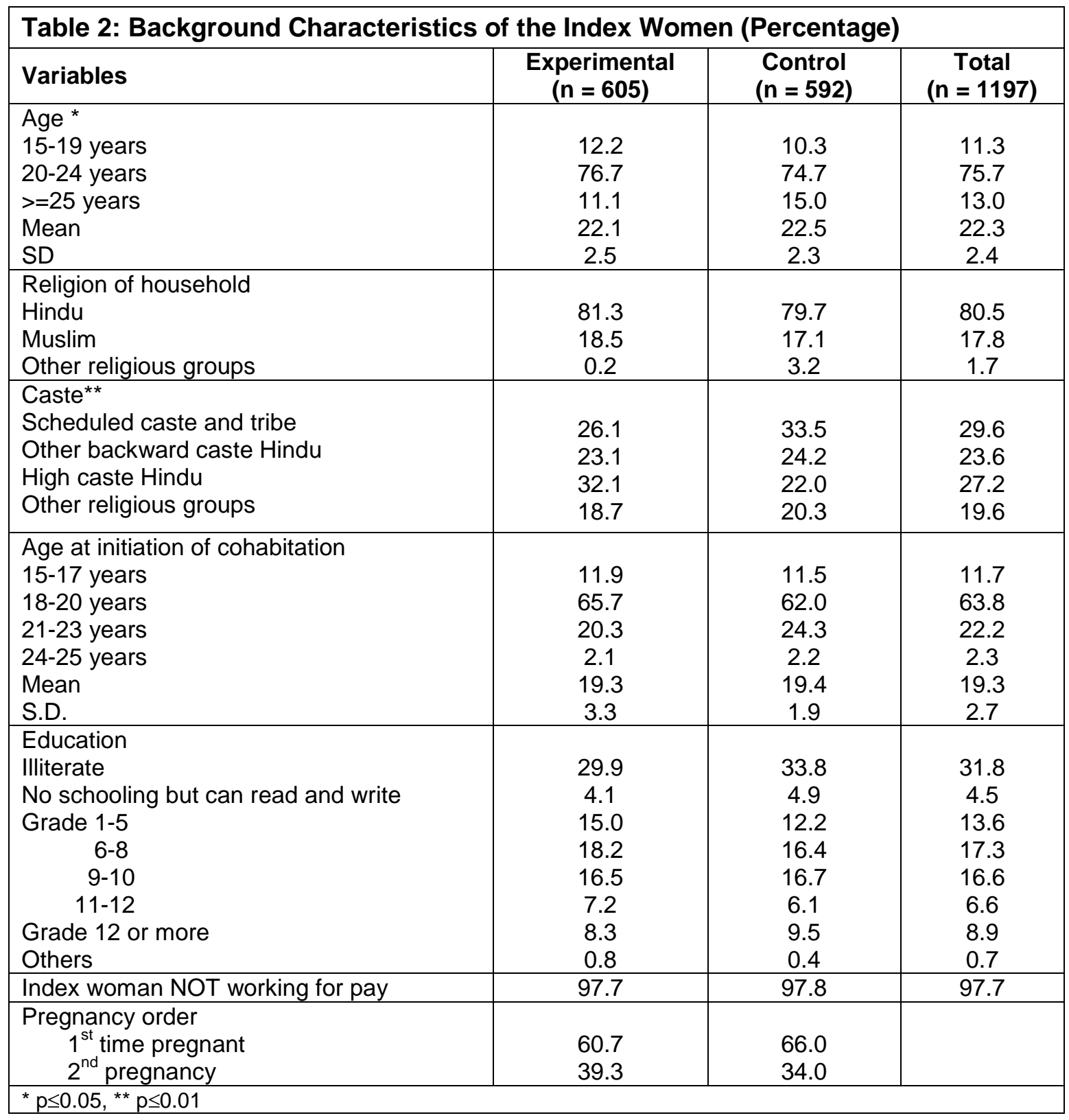




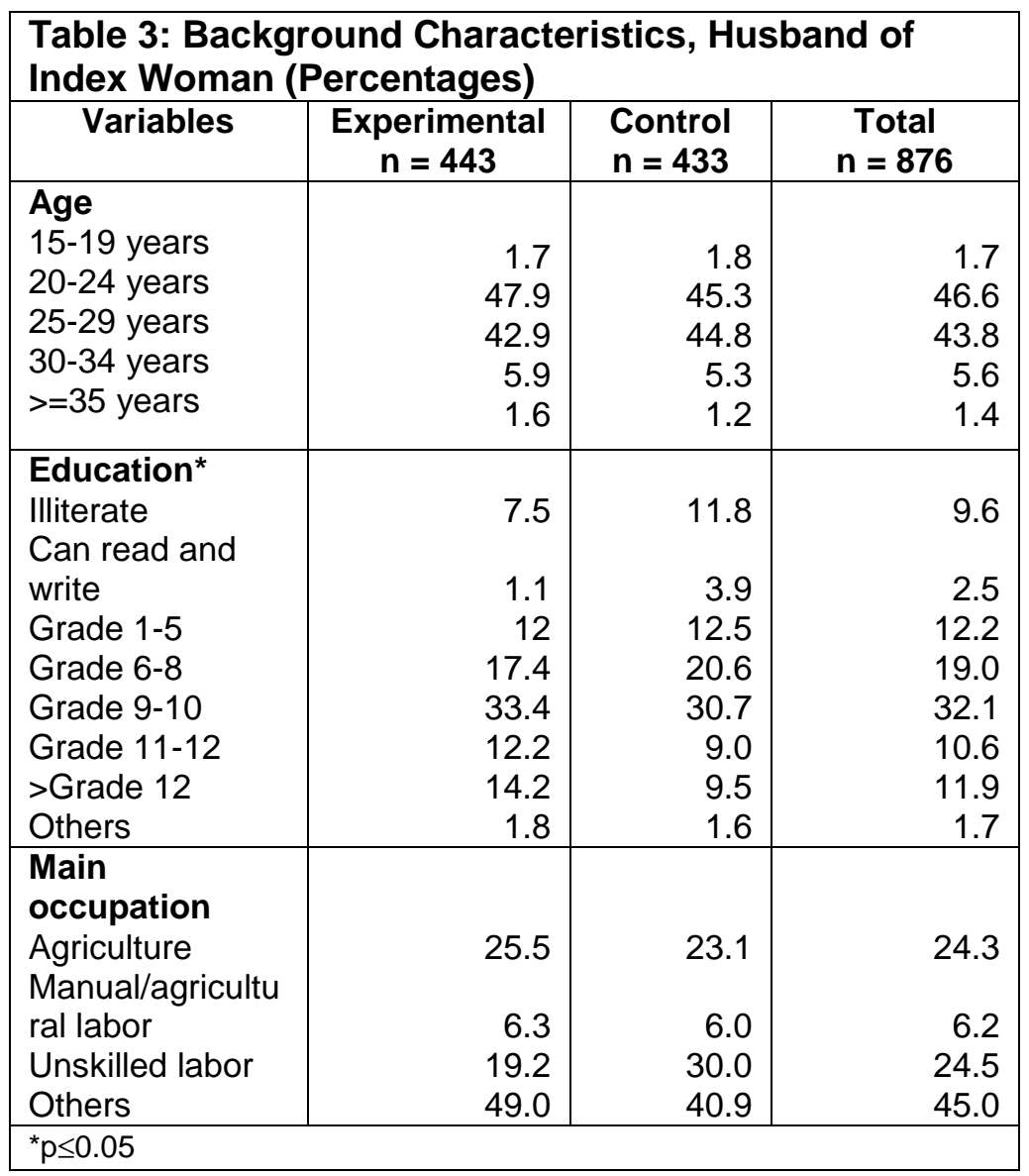

\begin{tabular}{|l|l|l|l|}
\hline \multicolumn{4}{|c|}{$\begin{array}{c}\text { Table 4: Background Characteristics, Mother-in-Law of } \\
\text { Index Woman (Percentages) }\end{array}$} \\
\hline Variables & $\begin{array}{l}\text { Experim } \\
\text { ental } \mathbf{n} \\
\mathbf{= 1 9 8}\end{array}$ & $\begin{array}{l}\text { Control } \\
\mathbf{n}=\mathbf{1 9 4}\end{array}$ & Total $\mathbf{n}=\mathbf{3 9 2}$ \\
\hline Age & 3.0 & 1.6 & 2.3 \\
$<35$ years & 5.1 & 3.1 & 4.1 \\
$\begin{array}{l}\text { 35-39 years } \\
\text { 40-49 years }\end{array}$ & 35.9 & 38.7 & 37.2 \\
50-59 years & 39.9 & 41.8 & 40.8 \\
$>=60$ years & 16.2 & 15.0 & 15.6 \\
\hline $\begin{array}{l}\text { Marital Status } \\
\text { Currently } \\
\text { married }\end{array}$ & 76.8 & 80.9 & 78.8 \\
$\begin{array}{l}\text { Widowed } \\
\text { Separated/ } \\
\text { divorced }\end{array}$ & 20.7 & 18.6 & 19.6 \\
\hline
\end{tabular}

